\begin{tabular}{|c|c|c|}
\hline IDUNAS & $\begin{array}{c}\text { NATURAL \& APPLIED SCIENCES } \\
\text { JOURNAL }\end{array}$ & $\begin{array}{c}2021 \\
\text { Vol. } 4 \\
\text { No. 1 } \\
\text { (15-21) }\end{array}$ \\
\hline
\end{tabular}

\title{
Domestic Software Developed for Updating of Finite Element Models and Experimental Modal Analysis of Structures
}

\author{
Research Article \\ Ahmet Can Altunışı1 ${ }^{1 *}$, Fatih Yesevi Okur ${ }^{1 * i D}$ \\ ${ }^{l}$ Department of Civil Engineering, Karadeniz Technical University, Trabzon, Turkey. \\ Author E-mails: \\ ahmetcan@ktu.edu.tr \\ yesevi@ktu.edu.tr \\ *Correspondance to: Ahmet Can Altunışık, Department of Civil Engineering, Karadeniz Technical University, Trabzon, Turkey. \\ DOI: 10.38061/idunas.851721
}

Received: 01.01.2021; Accepted:01.03.2021

\section{Abstract}

Reinforced concrete structures used in many areas of our daily life constitute an important part of the building stock in the construction sector. There are many buildings such as reinforced concrete buildings, bridges, tunnels, mosques and dams, and the construction of new buildings in line with the need continues. Many uncertainty factors play a role in the design phase of these structures from the dimensioning as a result of the analysis performed under the required loadings to the implementation phase in the field. Many unpredictable factors such as errors in the analysis, defects in materials and workmanship affect the success rate of the project of the structure. For this purpose, Experimental Modal Analysis method, which is widely used in the literature, is used to determine the success rate of new structures, to determine the dynamic characteristics and damage conditions of existing structures and structural health monitoring. Natural frequencies, which are the dynamic variables of the structure obtained by experimental modal analysis techniques, and mode shapes and damping ratios corresponding to these frequencies are used in the examination of the current state and structural properties of the structures. However, this experimental data can be obtained by with foreign-source software by allocating large budgets. The results of the native experimental modal analysis and finite element model update software developed within the scope of doctoral thesis are compared with the results of the existing software in the literature. As the application, raw signal data of Gülburnu Bridge and scaled Type-1 Arch Dam constructed in laboratory environment were used. The experimental results of the developed software and the existing software were found to be closely related to each other.

Keywords: Dynamic characteristics, Experimental modal analysis, Structural health monitoring.

\section{INTRODUCTION}

Experimental Modal Analysis method is used to determine the dynamic characteristics of the structures depending on experimental measurement methods. In this method, vibration signals from accelerometers placed on the structure are collected and dynamic characteristics are obtained from raw 
vibration data processed using up-to-date software. The determination of dynamic characteristics using analytical and experimental methods brings along the need to compare the results obtained and to interpret the differences between the results. Generally, the differences that may occur are due to uncertain parameters (material and section properties, boundary conditions) taken into account during analytical analysis based on finite element model. If the difference between analytical and experimental dynamic characteristics is around 5-10\%, it is accepted that the analytical dynamic characteristics reflect the current state of the structure. However, if this value is greater than 5-10\%, it is accepted that the analytical dynamic characteristics do not reflect the current state of the building. In this case, the finite element model of the structure should be improved according to the experimental measurement data [1-5]. Thus, the differences between the results are minimized and a finite element model reflecting the current state of the building is obtained.

Damage detection methods are generally based on the change of dynamic characteristics such as frequency, mode shape and damping ratio. Structures can be damaged over time for various reasons. For this reason, the structural conditions of engineering structures should be monitored periodically or continuously by experimental methods and the damage conditions should be determined early. Thus, future destructions can be prevented.

Within the scope of this study, the results of domestic software developed in order to obtain dynamic characteristics by processing experimental data (Dynamic Modal) and to detect damage by updating finite element models (Dynamic Update) were verified by comparing them with the literature.

\section{DYNAMIC MODAL}

With the Dynamic Modal software, dynamic characteristics are obtained from the experimental raw signals of the structures. Enhanced Frequency Domain Decomposition (EFDD) and Stochastic Subspace Identification (SSI) methods are used in signal processing. In EFDD Method, Fast Fourier Transform, Power Spectrum, Cross-Power Spectrum, Singular Value Decomposition methods are used. In SSI Method, the processes of creating past / future signals with the help of Hankel Matrix of signals in time environment, obtaining system matrices and determining the stability diagram are performed. Figure 1 presents some views of the Dynamic Modal software. As an example, the dynamic characteristics of the bridge were determined using raw signal data of Gülburnu Highway Bridge. Figure 2 presents some views of the Gülburnu Highway Bridge. The graphs of the results of the Dynamic Modal and Operational Modal Analysis [6] software are given in Figure 3.

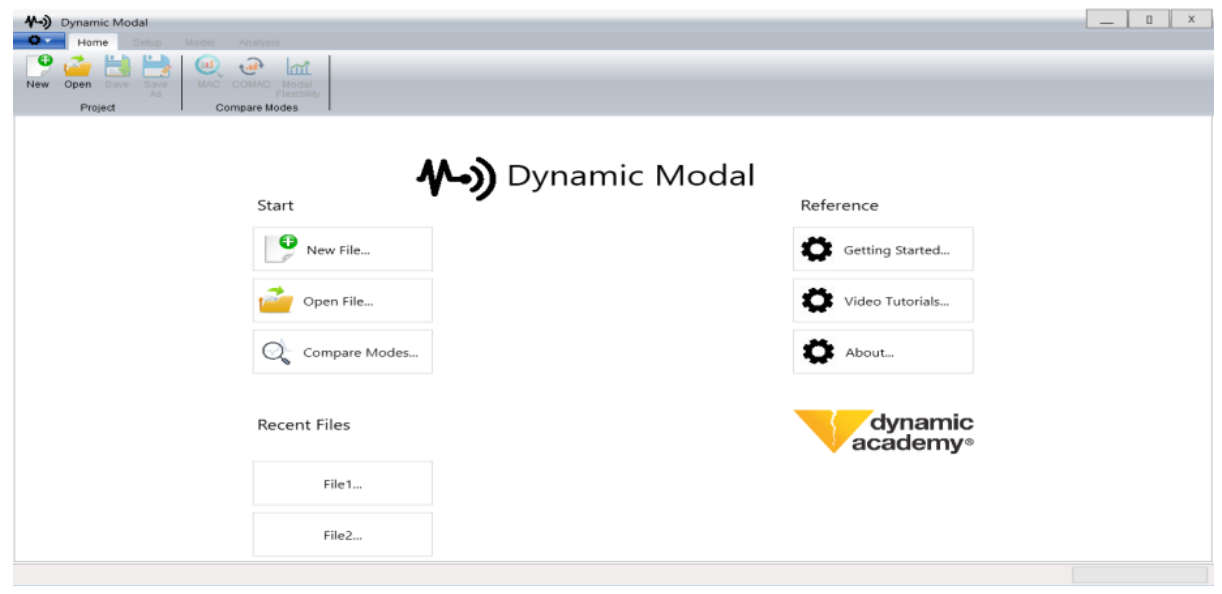

a) Login menu of Dynamic Modal software 


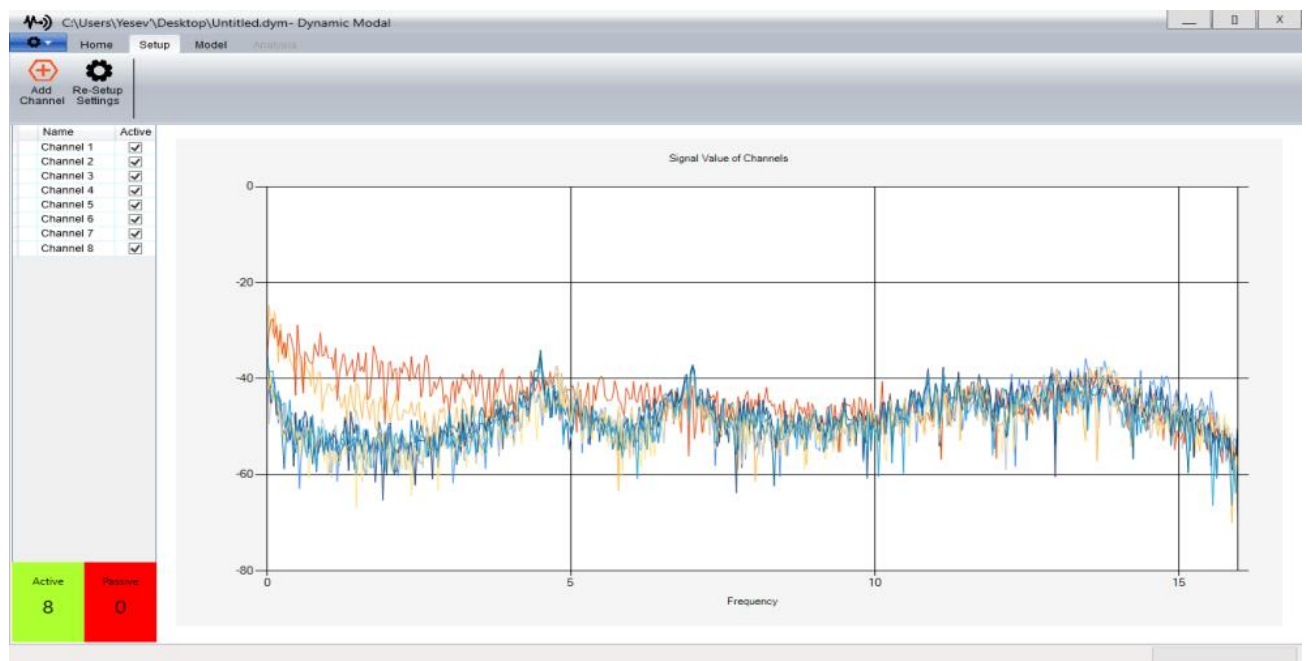

b) Transfer of raw signals to software

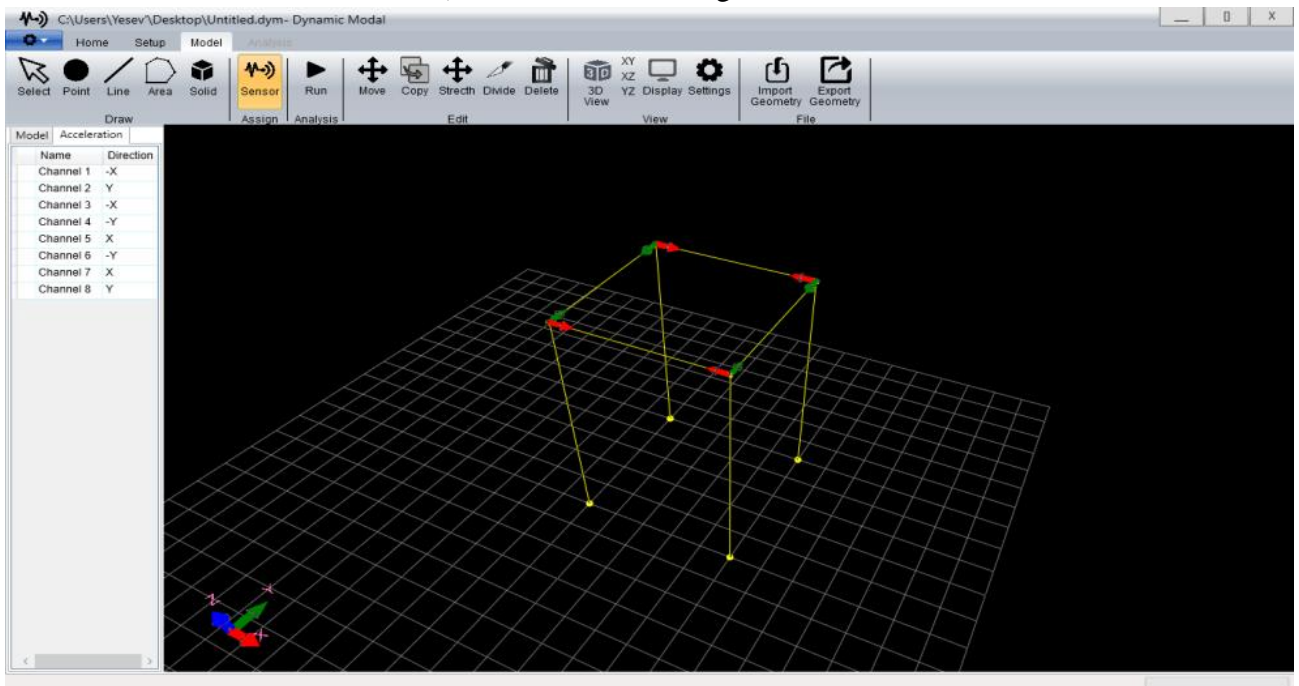

c) Creating the model geometry

Figure 1. Some images of Dynamic Modal software.
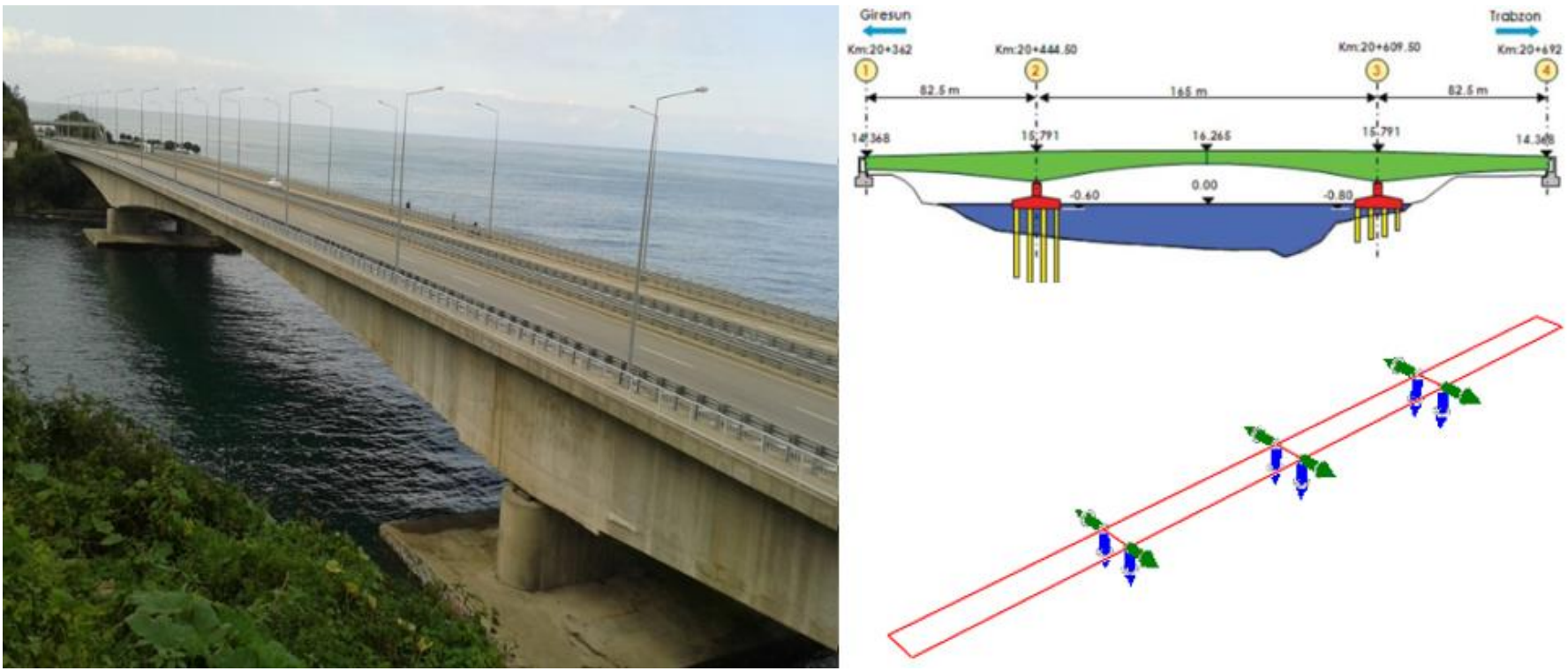

Figure 2. Gülburnu Highway Bridge. 

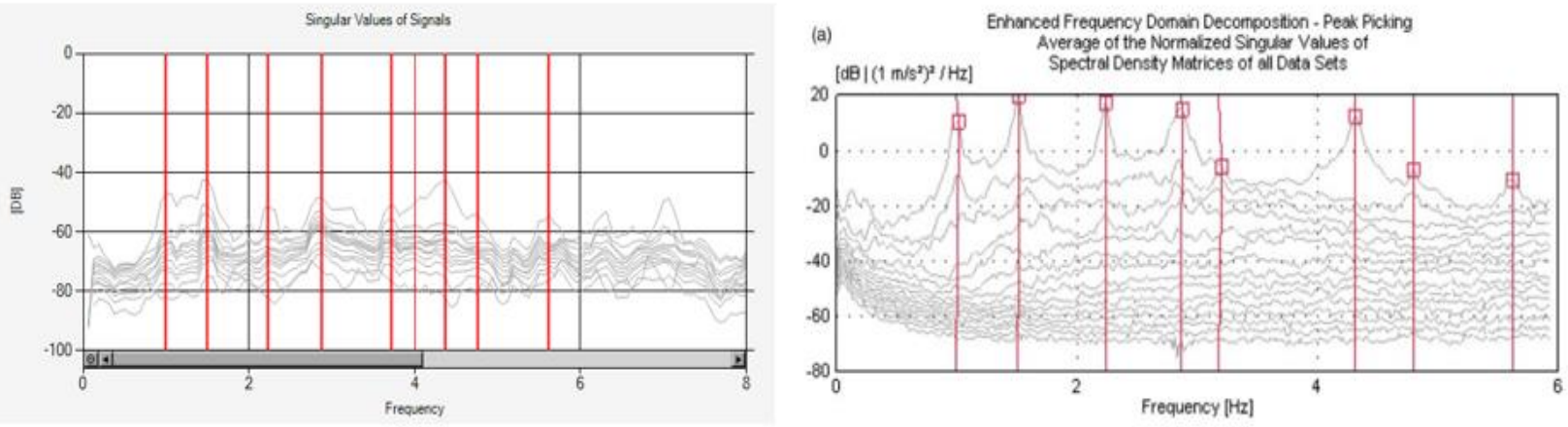

a) EFDD method
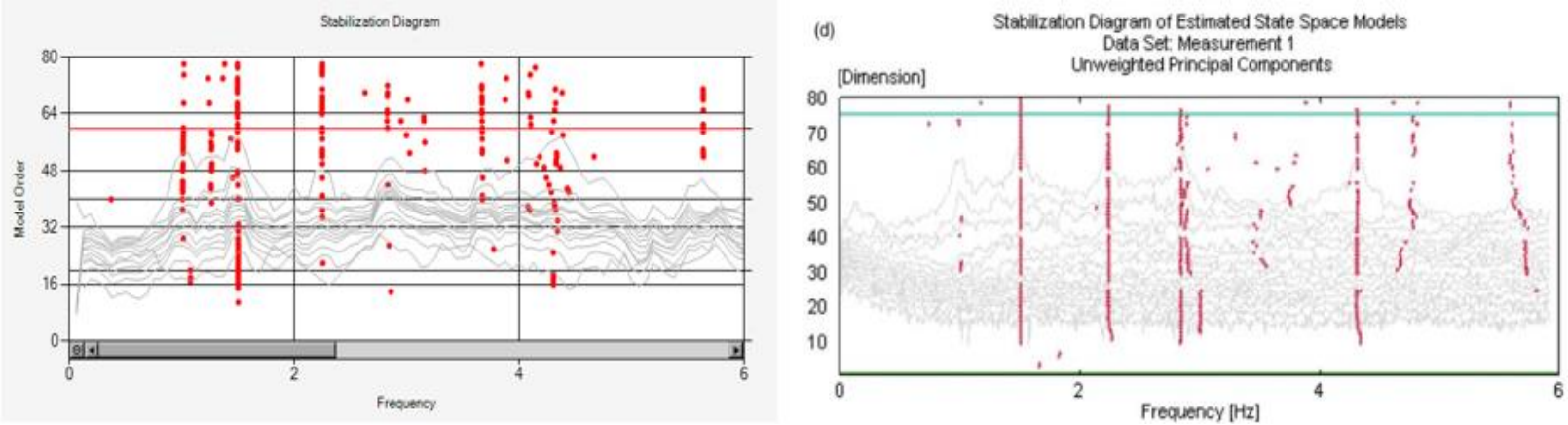

b) SSI method

Figure 3. Graphics obtained according to EFDD and SSI methods of Gülburnu Highway Bridge.

The frequency values obtained according to EFDD and SSI methods of Gülburnu Highway Bridge are given below. The results of the developed software are compared with the results of the Operational Modal Analysis [6] software. Table 1 shows the results and differences according to the EFDD and SSI method. The maximum differences obtained according to the EFDD and SSI method was 1.28\%, 2.18\%, respectively.

Table 1. Comparison of the results of Dynamic Modal and OMA software [6]

\begin{tabular}{|c|c|c|c|c|c|c|}
\hline \multirow[b]{2}{*}{ Mode No } & \multicolumn{3}{|c|}{ EFDD } & \multicolumn{3}{|c|}{ SSI } \\
\hline & $\begin{array}{c}\text { Dynamic } \\
\text { Modal }\end{array}$ & OMA & Diff. (\%) & $\begin{array}{c}\text { Dynamic } \\
\text { Modal }\end{array}$ & OMA & Diff. $(\%)$ \\
\hline 1 & 0,989 & 0,994 & 0,51 & 1,010 & 0,997 & $-1,28$ \\
\hline 2 & 1,489 & 1,508 & 1,28 & 1,492 & 1,505 & 0,87 \\
\hline 3 & 2,223 & 2,238 & 0,68 & 2,248 & 2,238 & $-0,44$ \\
\hline 4 & 2,877 & 2,860 & $-0,59$ & 2,790 & 2,850 & 2,15 \\
\hline 5 & 3,174 & 3,175 & 0,03 & 3,12 & 3,188 & 2,18 \\
\hline 6 & 4,362 & 4,314 & $-1,10$ & 4,338 & 4,335 & $-0,07$ \\
\hline 7 & 4,754 & 4,793 & 0,82 & $---{ }^{(*)}$ & 4,848 & --- \\
\hline 8 & 5,610 & 5,618 & 0,14 & 5,635 & 5,626 & $-0,16$ \\
\hline
\end{tabular}




\section{DYNAMIC UPDATE}

Comparison of experimental dynamic characteristics and finite element analysis results, ability to update finite element model under uncertain parameters, damage zone and damage level / severity can be evaluated by performing damage determination. In order to provide ease of operation, finite element model files (log file, s2k file etc.) created using different software can be easily transferred to the software. In this way, modal analysis results and dynamic characteristics can be obtained by extracting model coordinates and structural analysis parameters from the data file and using the created element matrices. By overlapping the results of the finite element model with the experimental results (especially the mode shapes), the differences between the dynamic characteristics can be calculated or the ratio of the fit can be calculated together with the MAC (Modal Assurance Criteria) and COMAC (Coordinate Modal Assurance Criteria). The improved finite element models obtained as a result of the sensitivity analysis can be transferred back to the desired finite element calculation programs. Figure 4 shows the login menu of the Dynamic Update software. The views of the modeling types made in the Dynamic Update software are given in Figure 5.

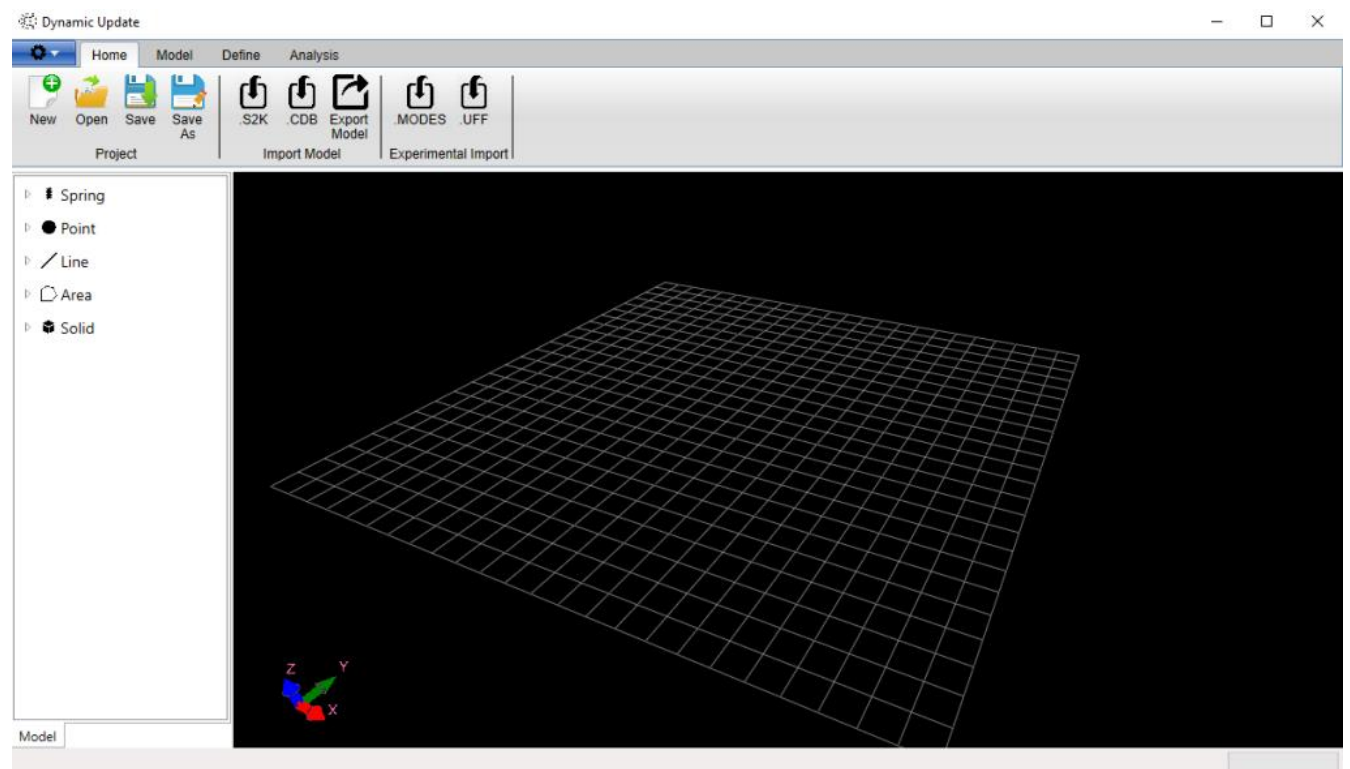

Figure 4. Login menu of Dynamic Update software.

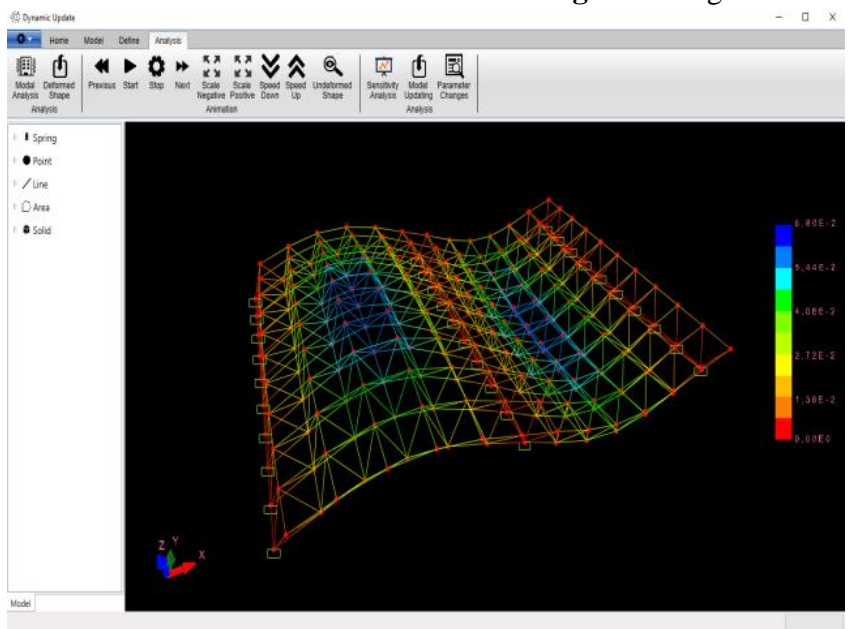

a) Frame elements

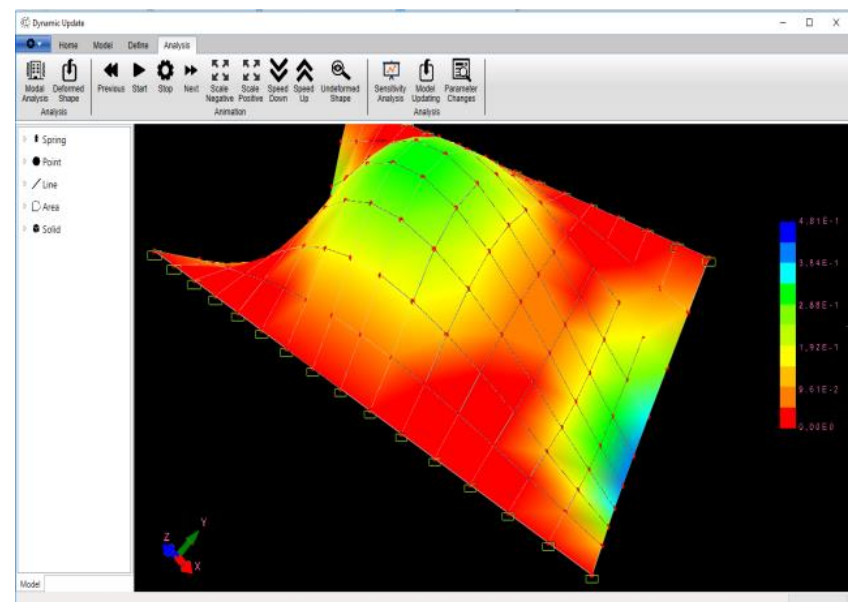

b) Area elements 


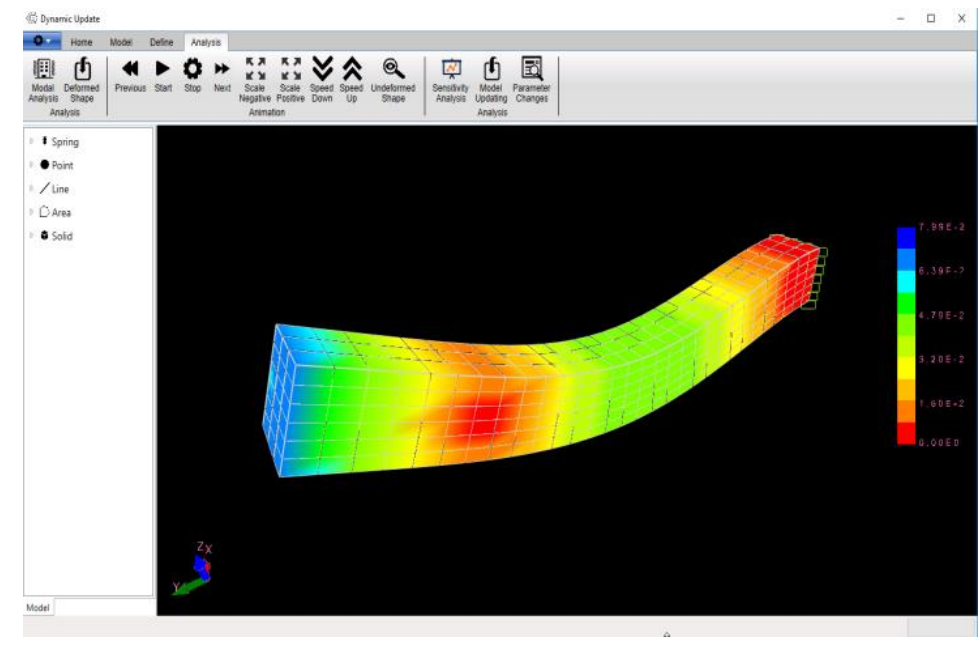

c) Solid elements

Figure 5. Some views to modeling types developed in the Dynamic Update software.

As a sample, damage assessment was made using the scaled Type-1 Arch Dam. The finite element model of the arch dam is given in Figure 6. The laboratory model, Type-1 Arch Dam, was damaged and experimental measurements of the damaged model were taken (Sevim, 2010) (Figure 7).

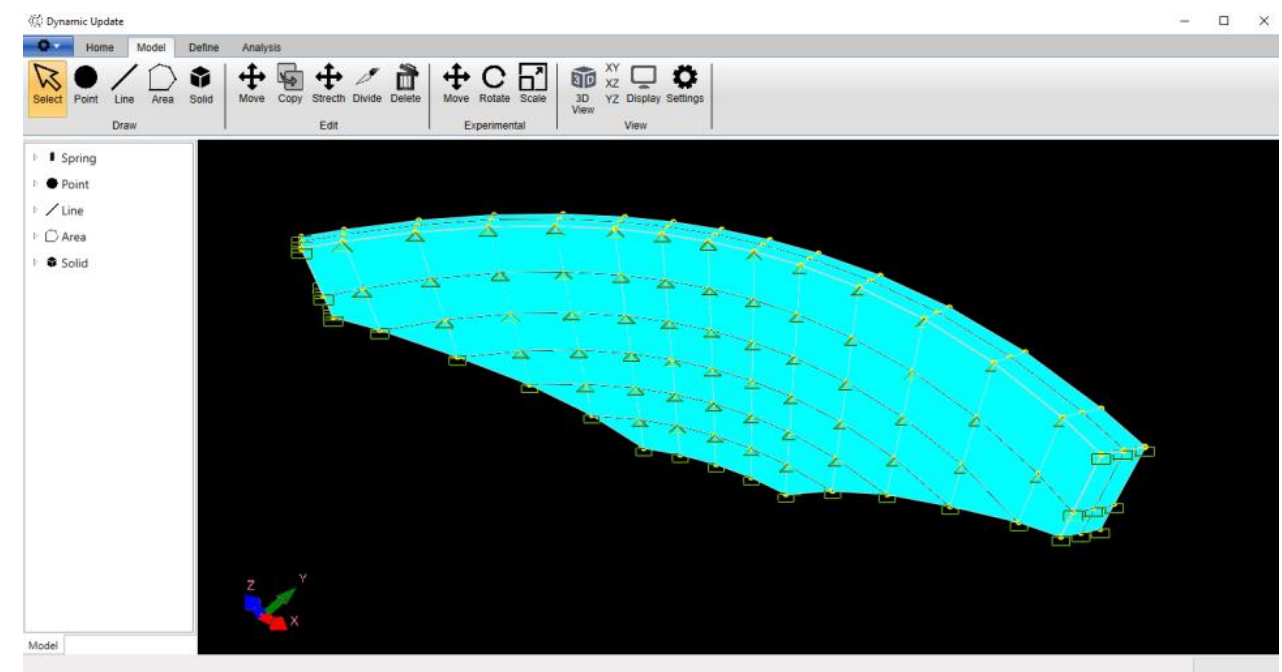

Figure 6. Finite element model of Tip-1 Arch Dam.

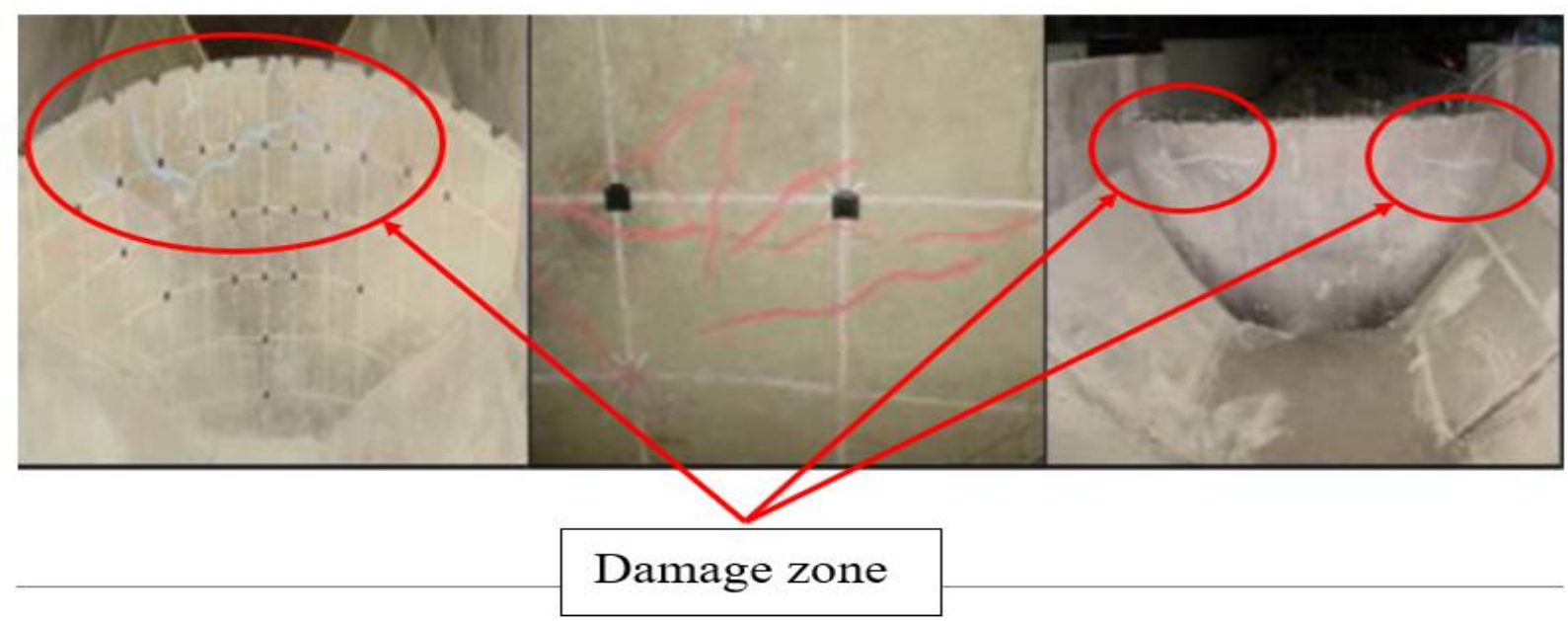

Figure 7. Experimental damage zones of Type-1 Arch Dam. 
Elasticity Modulus changes of the elements that have been updated locally of scaled Type-1 Arch Dam by using Bayesian Parameter Estimation Method based on sensitivity are given in Figure 8. It was seen that the results obtained were compatible with the experimental ones.

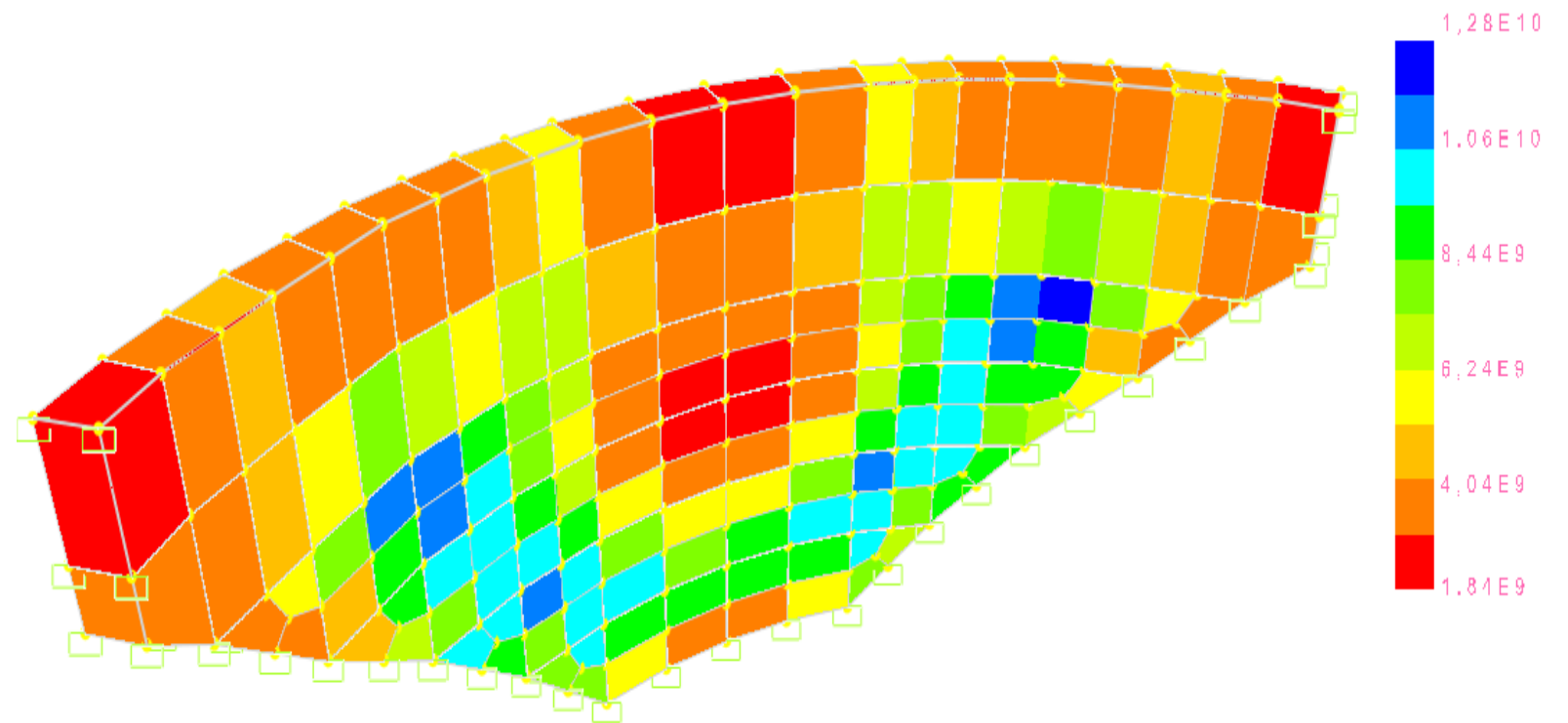

Figure 8. Numerical damage zones of Type-1 Arch Dam.

\section{CONCLUSION}

Foreign-sourced software requires high costs for important experimental work fields of civil engineering. With the help of domestic software, it is aimed that all academicians and researchers can reach the development of our country and these software with a lower budget. Dynamic Modal software for obtaining Experimental Modal Analysis results and Dynamic Update software for Model Update were developed. It was observed that the results obtained in the samples made within the scope of this study are compatible with the literature.

\section{REFERENCES}

1. Friswell, M. I., Mottershead, J. E. (1995). Finite element model updating in structural dynamics, solid mechanics and its applications, Kluwer Academic Publishers Group, 1-286, ISBN 978-07923-3431-6.

2. El-Borgi, S., Smaoui, H., Cherif, F., Bahlous, S., Ghrairi, A. (2004). Modal identification and finite element model updating of a reinforced concrete bridge, Emirates Journal for Engineering Research, 9(2), 29-34.

3. Modak, S. V., Kundra, T. K., Nakra, B. C. (2002). Comparative study of model updating methods using experimental data, Computers and Structures, 80(5-6), 437-447.
4. Jaishi, B., Ren, W. (2005). Structural finite element model updating using ambient vibration test results, Journal of Structure Engineering, ASCE, 131(4), 617-628.

5. Bayraktar, A., Altunışık, A.C., Sevim, B., Türker, T. (2007). Modal testing and finite element model calibration of an arch type steel footbridge, Steel and Composite Structures, 7(6), 487-502.

6. OMA. (2006). Release 4.0. Computer Software. Structural Vibration Solution, Aalborg, Denmark. 